Vol. 39(1), pp. 32-46, June 2020

ISSN 1821-536X (print)

ISSN 2619-8789 (electronic)
Tanzania Journal of Engineering and Technology Copyright (c) 2020 College of Engineering and

Technology, University of Dar es Salaam

Full Length Research Paper

\title{
Analysis of the Current Challenges for Deep Underground Mines: Labour Productivity Improvement
}

\author{
Jenny Greberg ${ }^{1}$ and Abubakary Salama ${ }^{2 *}$ \\ ${ }^{1}$ Department of Civil, Environment and Natural Resources Engineering, Division of Mining \\ and Rock Engineering, Luleå University of Technology, SE-971 87, Luleå, Sweden. \\ ${ }^{2}$ Department of Chemical and Mining, University of Dar es Salaam, Tanzania. \\ *Corresponding author Email: asalama@udsm.ac.tz
}

\begin{abstract}
With much of the ore deposits close to the surface already discovered and mined, the mines are becoming deeper, and this brings multiple challenges. One of the challenges is the longer haul distance from active mining areas to the mine surface, hence longer transportation time of material and operators. Longer transportation time of operators may lead to the reduction of the labour productivity. Labour productivity in today's mines is a key importance, and is currently dependent on together with other factors that operators should be at the vehicles or working area on time. There has been some development in mine automation, but the vast majority of underground mine operations are still in need of operators. Several methods are available and can be used to transport operators to the underground working areas. These methods include mine vehicles, mine taxis, mine buses, monorail, and shaft system. As mine depth increases, the method with higher labour productivity will be of much useful in operator's transportation. The aim of this study is to investigate personal transportation methods for deeper underground operations by comparing labour productivity when using mine vehicle, mine taxi, mine buses, and monorail system. The results show that mine vehicle has higher labour productivity of up to $76 \%$ of available time, while mine buses have low labour productivity. It has been reveal that for shallow depth mines, a good option to improve labour productivity is to have few operators transported per cycle, while for deep mines, a transport system that is faster, accommodate few operators per cycle, less possibility to meet traffic will be the better option for labour productivity improvement.
\end{abstract}

Keywords: Haul distance, Labour productivity, transportation method.

\section{INTRODUCTION}

With much of the ore deposits close to the surface already discovered and mined, the mines are becoming deeper, and this brings multiple challenges. Some of the challenges include ventilation costs due to high heat, high reinforcement costs due to higher rock stresses, logistics in transporting the material and personnel due to increase in haul distance (Salama et al., 2014). When haul distance is further increased, delays in personnel transportation may lead into reduction of labour productivity. Some underground mines have automated virtually pieces of mining equipment to some degree. Some types of equipment have been automated 
to the degree of having the operators removed completely from the face, and in some cases from the underground environment entirely, while other types of equipment have only benefitted marginally (Noort and McCarthy, 2008). Beside the advancement of automation, the operations in the underground mine are still dependent on people which operate the vehicles, sitting inside or being close to the vehicles. To optimize operator's productivity, the pertaining human factors must be studied (Coelli et al., 2005), which are human factors that directly affect productivity are labour utilization and labour productivity (Tomlinson, 1998; Aljuhani, 2002; Coelli et al., 2005; Bradley and Sharpe, 2009; Angelov and Naidoo, 2010). Labour productivity describes the relationship between output and the labour time involved in its production (Bureau of Labor Statistics, 2011). In the context of this paper it refers to the percentage of time the operators need to be at the active working areas or mine faces. Therefore, improving the labour productivity is one of the greatest savings in manpower and hence increases equipment effectiveness.

Numerous researchers have focused on determination of labour productivity and logistics plans rather than comparing the labour productivity for various transportation methods. Aljuhani (2002) investigated labour productivity and labour utilization for the purpose of improving productivity. He revealed that over $30 \%$ of available time, workers spent on nonproductive activities and hence reduces the productivity. Angelov and Naidoo (2010) analysed the effectiveness of the planning process as well as execution of mine plans. They revealed that the productivity should be improved throughout the value chain with the aim to improve grade control, equipment utilization, and labour productivity. Rupprecht (2010) investigated safety considerations in vertical, horizontal and in-stope underground transportation system. He concluded that transport of personnel should be operated in accordance with strict schedule, and that supervision must be improved to ensure people work to procedures. Syed et al. (2013) describe the overview of productivity growth in Australia mines. As part of their findings, they revealed that labour productivity is affected by travelling time to the workplace, operator efficiency, mechanical availability of equipment, and non-input factors such as technological progress.

Logistics play a significant role in the overall safety in mining because it involves transportation of personnel, material and rock from surface mine or from the working faces. The logistics aspect becomes exponentially more important as the mining goes deeper and the mine layout becomes increasingly stretched (Rupprecht, 2010). Traditionally, it is handled as a follow-up to the choice of mining method, but with an ineffective position of the crusher, lack of a clear schedule, ineffective use of available resources the amount of lost time and money is very significant. Possible solutions are to come up with a more timeand cost-effective way to use the resources and consistent strategic and tactical logistic plans to optimize the mine layout and operation, and increasing the mean effective time to decrease the overall costs (Misungwini et al., 2006).

Several methods are available and can be used to transport operators to the underground working areas. Example of these methods include mine vehicles, mine taxis, mine buses, monorail, and shaft system. As mine depth increases, the method of mine operator's transportation is crucial for higher labour productivity. The aim of this study is to investigate personal transportation methods for deeper underground operations by comparing labour productivity when using mine vehicle, mine taxi, mine buses, and 
monorail system. The analysis was conducted using analytical method. Analytical methods use mathematical principals to fully predict a theory's implications and can provide solutions without any estimation. Analytical methods have been widely used for many years in both open pit and underground mining operations to evaluate load and haul combinations, including production constraints such as road conditions and rock characteristics (Ercelebi and Kirmanli, 2000).

\section{METHODS AND MATERIALS}

\section{Case Study}

Two underground mines namely Mine A and Mine B located in Sweden were used for the purpose of investigating the personal transportation methods by comparing labour productivity when using mine vehicle, mine taxi, mine buses, and monorail system. Mine A has been in continuous operation since 1940 and uses conventional cut and fill mining method for exploitations (Figure 1).

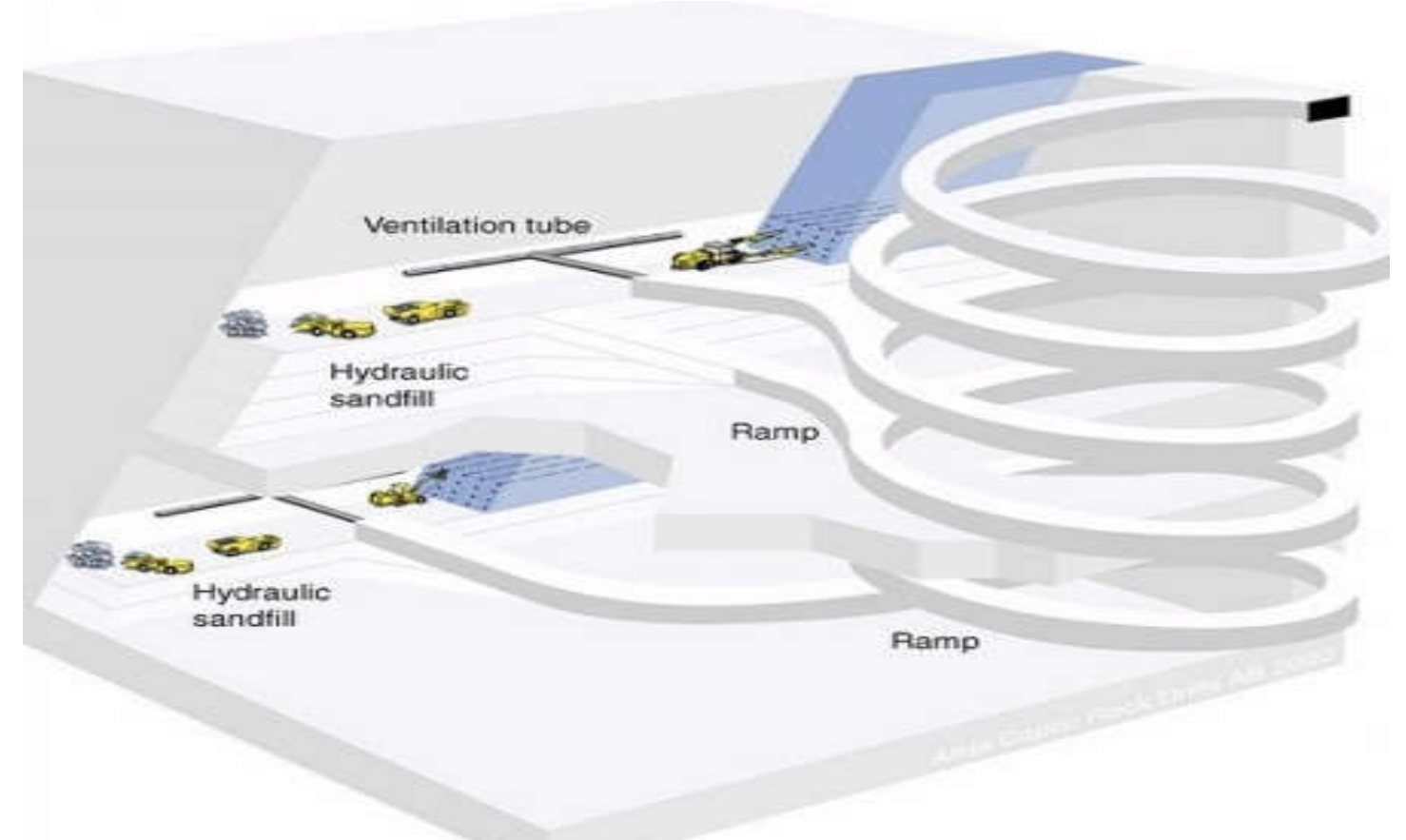

Figure 1: Mine structures during cut and fill production

The ore mined contains copper, silver, gold and zinc compounds. The mined out materials are loaded and transported to the crusher using trucks. The main logistical challenge is the need to transport big volumes and personnel to the working areas on time. Currently, the personnel are transported to underground using shaft and mine vehicles. The mean distance the workers need to cover to get to the active face is currently about $6 \mathrm{~km}$, and takes 20 30 minutes in one way transport. At the start of the shift, all mine vehicles parked at the shift change area and operators drive themselves to various work locations. Currently, the mine is researching the possibilities of optimizing the logistics and finding out more efficient ways to deal with the existing challenges.

Mine B started the mining operations since 1900. It is the world's largest underground iron ore mine producer. Currently, the main levels are located at 1000 and 1250 meters, whereas the new haulage level will be located at 1500 meter level. The mine uses sublevel caving mining method (Figure 2). The method requires sublevel 
drifts where ore can be blasted and allowed to cave into the tunnel. The mined out rock is picked from the draw points, normally by the front-end loader truck or LHD and transported to the dumping point. The mine utilizes mine vehicle and mine bus for personnel transportation to the working locations. Mine buses can make several trips to transport operators to the work locations. Therefore, this study was conducted to analyze labour productivity by comparing different transportation methods at various initial travel times from the shift change areas to various work locations. The objective was to determine the effective working time for deeper mine operations.

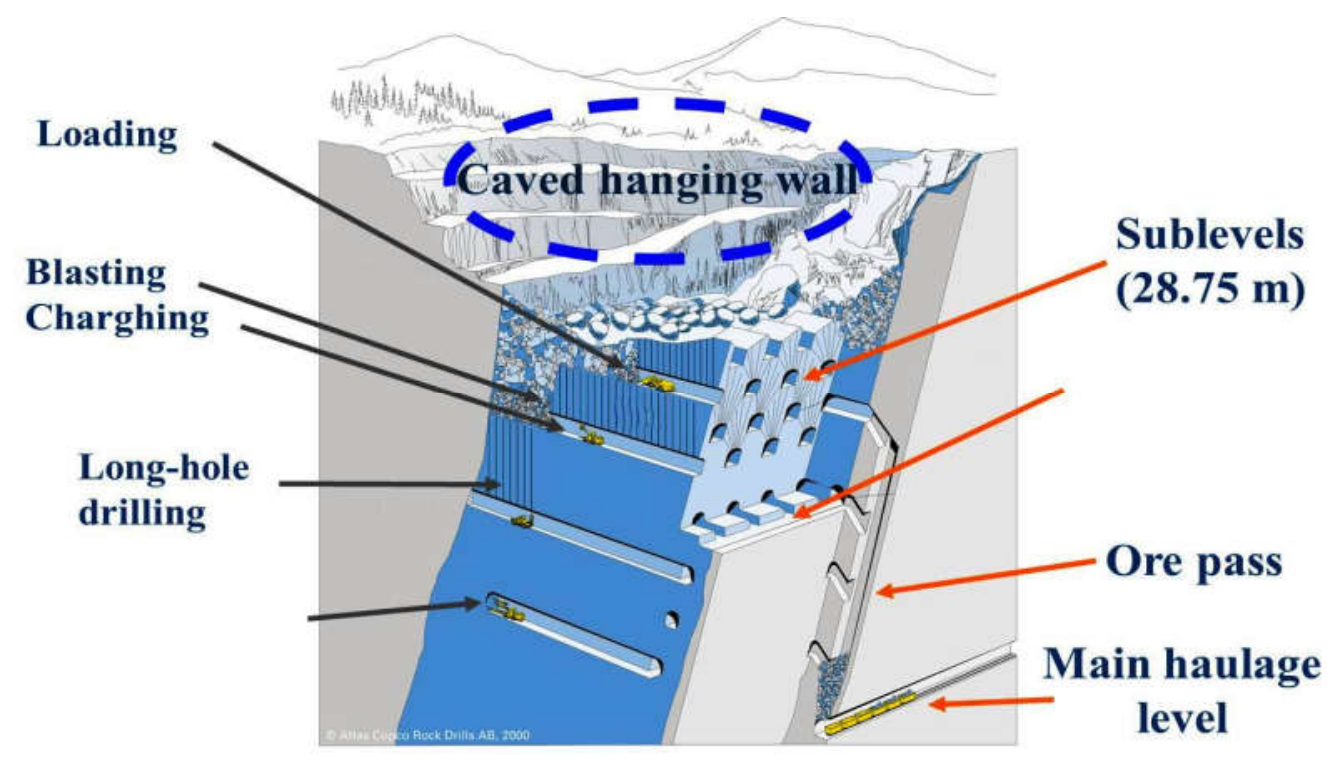

Figure 2: Mine structures during sublevel caving (Courtesy of LKAB)

\section{Mode of Transportation}

The mode of personnel transportation methods for deeper underground operations was investigated by comparing labour productivity when using mine vehicle, mine taxi, mine buses, and monorail system. In each case, operators are transported to their working areas or equipment, lunch room, and to or from mine surface. Table 1 shows these transportation methods and their descriptions.

\section{Mine Vehicle}

In this mode of transport, the operators drive themselves to the intended locations using light vehicles. In this case the travel is done at the beginning, during breaks, and end of the shift from their mine equipment (i.e. their working areas), or from the break rooms or from mine surface. In this type of transport, one or two operators can use the vehicle to the working location. Once the operator reaches the working area, mine vehicle will be parked and will be used during breaks or end of the shift.

\section{Mine Taxis}

Mine taxis include one or more common light vehicles which will pick up operators at specific times to various work locations around the mine. They are flexible and require no additional skills other than a drivers permit to drive underground. The destinations are chosen due to proximity of work locations. Unlike mine vehicle, once mine taxi arrives at the intended locations, it can go back to pick up other operators. Mine taxis can move up to five operators at a time. For mine taxis the drivers are not 
among the operators, and therefore no time

loss in finding a parking space.

Table 1: Mode of transportation

\begin{tabular}{|c|l|c|}
\hline Scenario & \multicolumn{1}{|c|}{ Description } & $\begin{array}{c}\text { Number of } \\
\text { people }\end{array}$ \\
\hline Mine vehicles & $\begin{array}{l}\text { Currently, used for both mines, operated by one of the } \\
\text { worker, car parked and wait for workers to end of shift }\end{array}$ & 1,2 \\
\hline Mine taxis & $\begin{array}{l}\text { Operated by a driver and drop the workers, then the } \\
\text { driver leave with a car }\end{array}$ & $2,3,4,5$ \\
\hline Mine buses & $\begin{array}{l}\text { One bus picking up many people to be analysed in both } \\
\text { mines }\end{array}$ & $6,7,8,9,10$ \\
\hline $\begin{array}{c}\text { Monorail } \\
\text { system }\end{array}$ & $\begin{array}{l}\text { A monorail system, much like mine buses to be analysed } \\
\text { in both mines }\end{array}$ & $6,7,8,9,10$ \\
\hline
\end{tabular}

\section{Mine Buses}

Mine bus is the transportation method whereby many operators can be transported to the working location. Despite that the mine buses can carry many people at the same time; their sizes may limit them to travel near the working equipment or mine areas. This would require an operator to get themselves to the working location. The aim of using mine bus is to check the possibility of moving many people at a time. For comparison purpose, number of operators was limited to ten per trip.

\section{Monorail System}

The technology has been developed in Jundee mining operations in Australia with the capability of drilling, blasting and hauls from the decline development (Chanda and Besa, 2011). The system is independent of the quality of the floor since it is mounted in a roof which allowing flexibility of track less arrangements. Monorail shares some of the characteristics with mine buses in the sense that it can transport more operators to their equipment or mine areas. When the mine expands, the monorail system can be expanded to limit the distance each operator has to travel to the working location. Since monorail is mounted in the roof, it is not affecting any traffic disturbances on the ramp, and it can be used for ore or waste transportation during the times when it is not transporting operators. For mine A, the monorail starts at distance of $500 \mathrm{~m}$ from the entrance of the main ramp. The distance between drop-off can be located at every $200 \mathrm{~m}$ within the ramp. When work is more spread out, the distance between drop-off could be increased.

Currently, Mine A uses mine vehicle, while Mine B uses mine vehicles and buses to transport operators to work locations. The other transportation methods (taxi and monorail) were evaluated to see the possibility of improving the labour productivity in comparison with the current situation. In each of the scenarios, the analysis was done for various initial travel times and average time between drop-off. Initial travel time is the time taken to transport an operator from parking area/start location to the first drop-off point (first reached working area). Data obtained from the mines reveal that the initial travel time varies from 10 to $25 \mathrm{~min}$. The transport time between drop-off is the average time taken for a vehicle to transport operators on work locations. Data obtained from both mines shows that the average transport time per drop off varies between 4 to $16 \mathrm{~min}$. During analysis, the average 
transport time of $4,8,12$, and $16 \mathrm{~min}$. were used.

\section{Input Data}

Data were collected for a period of three months from both mines. Table 2 shows some of the data used in this analysis which include idle time, non-productive time, shift breaks, work length, travel time, spare time, and operator's waiting time.
The time delay at the start and end of the shift, and the time when vehicle stop to drop off the operators are also included in the analysis. For analysing monorail, data were estimated based on the each mine's conditions. The idle time represents the average time where a vehicle start late and quit early. Non-productive time represents the time that equipment undergoing minor services such as refuelling, etc.

Table 1: Input data for labour productivity estimation

\begin{tabular}{|l|c|c|c|c|}
\hline Input & $\begin{array}{l}\text { Mean values } \\
\text { for Mine A } \\
\text { (Minutes) }\end{array}$ & $\begin{array}{l}\text { Mean values } \\
\text { for Mine B } \\
\text { (Minutes) }\end{array}$ & $\begin{array}{l}\text { Values } \\
\text { Monorail at Mine } \\
\text { A (Minutes) }\end{array}$ & $\begin{array}{l}\text { Values for Monorail at } \\
\text { Mine B (Minutes) }\end{array}$ \\
\hline Idle time & 7 & 8 & 7 & 8 \\
\hline Non-productive travel time & 7 & 9 & 264 & 12 \\
\hline shift work length & 264 & 228 & $15-25$ & $15-25$ \\
\hline Initial Travel time & $15-25$ & $15-25$ & $4,8,12$ and 16 & $4,8,12$ and 16 \\
\hline $\begin{array}{l}\text { Average transport time } \\
\text { between drop-off }\end{array}$ & $4,8,12$ and & $4,8,12$ and & 16 & 5 \\
\hline Spare time & 5 & 5 & 2 & 2 \\
\hline Operator's waiting time & 2 & & & 2 \\
\hline
\end{tabular}

Figure 3 shows the various activities (described as input in Table 2) for mine A which were used to calculate the idle and non-productive times. Figure 3 reveals the different work periods with several breaks between them. It can be seen that the closer to the break, the less number of activities are performed. This is because in most cases, operator starts later than the required time after any break or at start of shift. Also operators stop working earlier than the required time before any break or at the end of the shift. Breaks during the shift which were used for all transportation methods are $2.4 \%$ and $4 \%$ of the total shift time for mine $\mathrm{A}$ and mine $\mathrm{B}$, respectively.

The analysis was conducted based on the continuous working period. The current shift schedule at Mine A has an average length of $528 \mathrm{~min}$. (after excluding all breaks). The $528 \mathrm{~min}$. shift results in an average continuous work period of 264 min. While for mine $B$ the average continuous work period was 228 min.

Table 3 shows data used for monorail in both mines. A monorail system can be seen as a roof-mounted rail, where a train travels. A monorail system might coexist with ventilation tubes in the roof and can be used for ore transport during the times when it is not transporting people. The monorail transport system is comprised of vehicles forming a flexible train unit and can be equipped with personnel cabins (Figure 4), material containers, and bottom discharge hoppers for material handling as well as man haulage. 


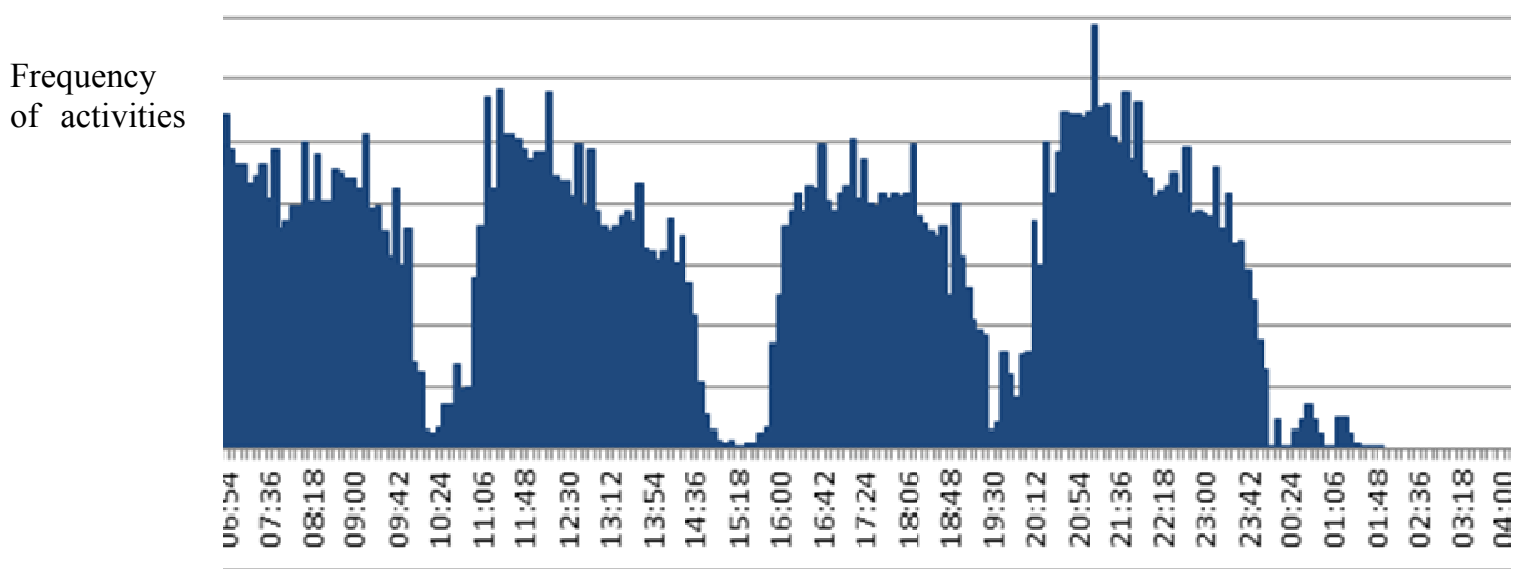

Figure 3: Activity during a day for mine A

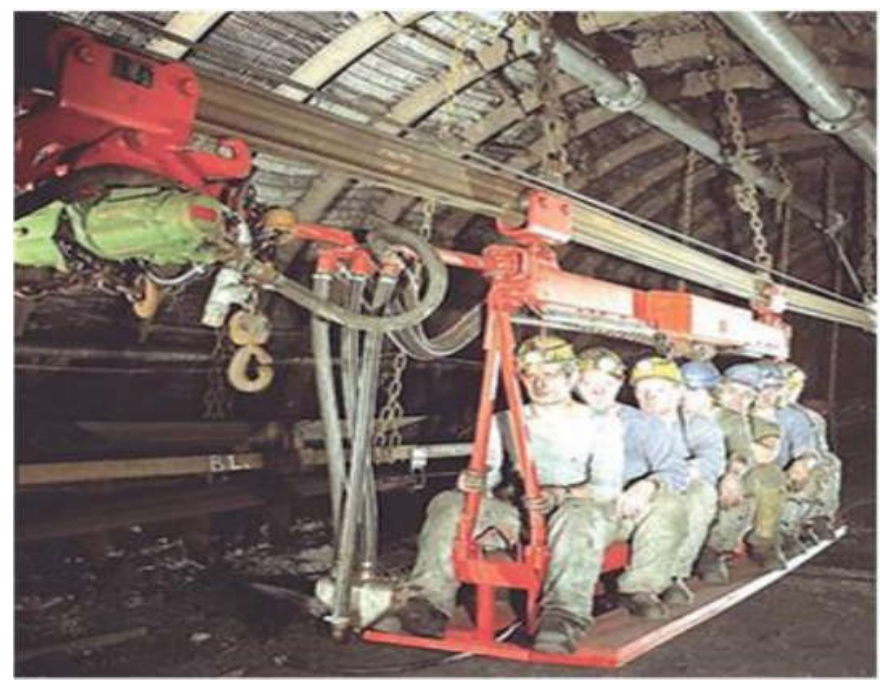

Figure 4: Transport of men (adopted from Chanda and Roberts, 2005)

A rail track is anchored and suspended from the hanging wall and operated by electrical, diesel or battery drives. A conductor rail, which is bolted directly to the rail supplies the energy required to drive the train. Electro monorail can be used in underground hard rock mines with small cross sections and long inclines and with the gradient of up to $34^{\circ}$, payloads of up to 30 tonnes per single loading for all containers at low energy consumption and easy maintenance (Chanda and Roberts, 2005). A single container can carry a maximum of 5 tonnes and a total monorail contain of six containers and by mounting man-riding it can carry up to 20 men (Chanda and Burke, 2007). The use of monorail system will results into lower support costs, reduction of the supplied air for ventilation, and minimal diesel exhaust fumes. Based on the mines infrastructures, the analysis was conducted at the depths of $1000,2000,3000$, and 4330 meters from the mine surface. The monorail will first stop at a depth of $200 \mathrm{~m}$, and thereafter stops at every $500 \mathrm{~m}$ to drop operators at the work locations. 
Table 2: Input data for monorail in both mines.

\begin{tabular}{|l|c|c|}
\hline \multicolumn{1}{|c|}{ Input } & Values used at Mine A (m) & Values used at Mine B (m) \\
\hline Mine depths (m) & $1000,2000,3000,4330$ & $1000,2000,3000,4330$ \\
\hline $\begin{array}{l}\text { Average distance between } \\
\text { drop-off and pickup (m) }\end{array}$ & 200, then at every 500 & 200, then at every 500 \\
\hline $\begin{array}{l}\text { Average time to get off or in } \\
\text { the monorail transport (min) }\end{array}$ & $0-1$ & $0-1$ \\
\hline Average travel speed (m/s) & $3-5$ & $3-5$ \\
\hline
\end{tabular}

\section{Analysis of Labour Productivity}

As seen equation (1), labour productivity is the percentage of time that the work force or individual operators are at the work site with tools performing productive job (Tomlison, 1998).

$P=\frac{T_{e}}{T_{\text {shift }}} \times 100 \%$

Where $\mathrm{P}$ is labour productivity, $\mathrm{T}_{\mathrm{e}}$ stands for effective work time, and $T_{\text {shift }}$ represents the available time for work. The effective work time was calculated as seen in equation (2).

$T_{e}=T_{\text {shift }}-T_{n}$

Where $T_{n}$ is non-efficient time. This is the time when the operator is doing something else other than operating the machine, such as minor break and refuelling. The nonefficient time can be calculated as seen in equation (3).

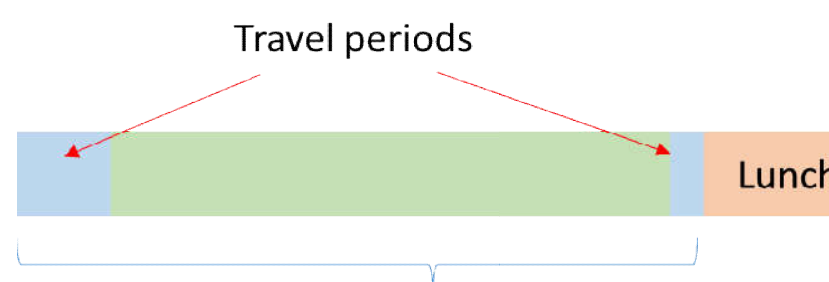

Work period 1

$$
T_{n}=T_{t}+T_{o}+T_{m b}+T_{n p t}
$$

Where $T_{t}$ is the total travel time to or from the working area, $T_{0}$ stands for other idle time, such as late starts and early quits. $\mathrm{T}_{\mathrm{mb}}$ represents time for minor breaks, such as chats, smoke pauses etc. $\mathrm{T}_{\mathrm{npt}}$ is nonproductive travel time, for refuelling, fetching material etc. $\mathrm{T}_{\mathrm{mb}}$ can be calculated as shown in equation (4).

$T_{m b}=T_{\text {shift }} * T_{m b} \%$

Where $\mathrm{mb}_{\%}$ stands for the percentage of the shift time for minor breaks. Normally, for most of the operating mines, people transportation happens twice during each continuous work period. Continuous work period is defined as the work period before and after main break until end of the shift. A full shift usually contains one lunch break, which creates two continuous work periods (Figure 5).

Figure 5: Continuos work period

The total travel time to or from the working areas was calculated as seen in

$$
T_{t}=T_{t m}+T_{f m}+T_{\text {common }}
$$
equation (5). 
Where $T_{\mathrm{tm}}$ is travel time to the working area from the shift start location, $\mathrm{T}_{\mathrm{fm}}$ stands for travel time from machine to the shift end location. The shift end and start locations could be where the transport drops the operators or picks them up. $\mathrm{T}_{\text {common }}$ is the common travel time occurring at the start and end of each shift. The average transport time for each person travelling to and from the working areas depends on number of persons in the same transport and time between each drop-off location. Any time for a person to get off the transport will be included in the time between drop-offs. The travel time $\left(\mathrm{T}_{\mathrm{tm}}\right)$ can be obtained using equation (6).

$T_{t m}=T_{f}+\frac{n+\frac{T_{t b d 2}+T_{t b d n}}{2}}{n}$

Where $T_{f}$ is the initial travel time until the first working area is reached, $\mathrm{T}_{\mathrm{tbd}}$ is time to travel between drop-off locations, $\mathrm{n}$ is number of persons transported by one vehicle. The travel time from machine to the shift end location is calculated as seen in equation (7).

$T_{f m}=T_{t m}+T_{g w}+T_{t s}$

Where $T_{\mathrm{sw}}$ is the time when the operator is waiting for the transport to arrive, $\mathrm{T}_{\mathrm{ts}}$ is the time to spare for the transport and until the break starts. The labour productivity can be re-written as shown in equation (8).

The labour productivity for two operating mines when using mine vehicle, mine taxi, mine buses, and monorail system were calculated and compared. The methods with higher labour productivity were recommended in operator's transportation.

$$
P=\frac{T_{\text {shift }}-\left(\left(2 *\left(T_{f}+\frac{n * \frac{T_{t b d 2}+T_{t b d n}}{2}}{n}\right)+T_{g w}+T_{t s}+T_{\text {common }}\right)+T_{o}+\left[T_{\text {shift }}+m b \%\right]+T_{n p t}\right)}{T_{\text {shift }}}
$$

\section{RESULTS AND DISCUSSION}

The analysis was first conducted for the first mode of personnel transportation, which involves the use of mine vehicle. The results are presented for variable continuous time, average transport time between work locations, and initial travel times for both mines. The current shift schedule at mine $\mathrm{A}$ has an average length of $528 \mathrm{~min}$., which gives a continuous work period of 264 min., while for mine B the average continuous work period was 228 minutes. In both cases, average transport time (displayed as tbd in Figures 6,7 , and 8 ) of $4,8,12$, and 16 minutes, and the initial travel time varies between 15 and 25 minutes were used. The relationship between labour productivity, number of people per transport, and average transport time between work locations (tbd) for mine A were evaluated. During data collection in the mines it was observed that for mine $\mathrm{A}$, mine vehicles were carrying 1 or 2 operators per transport. As it can be depicted in Figure 6, an increased number of operators per vehicle lead to decreased labour productivity. It shows that, the labour productivity was $76.4 \%$ with one operator per vehicle, but decreased to $74.9 \%$ when there are two persons in a vehicle for the case when a low initial travel time were used. The reduction of labour productivity was because of the time lost when a vehicle stop to drop the operator to the intended locations. This means that when this kind of transport is used, the labour 
productivity can be improved if operators sharing the same transport are located in a closely working environment.

It was observed that, when the initial travel time is increased to $25 \mathrm{~min}$. (Figure 7), the labour productivity with one operator per vehicle was $68.8 \%$, but reduced to $67.3 \%$ when there are two persons in a vehicle. This shows that the longer initial travel time results in the reduction of labour productivity by $7.6 \%$.

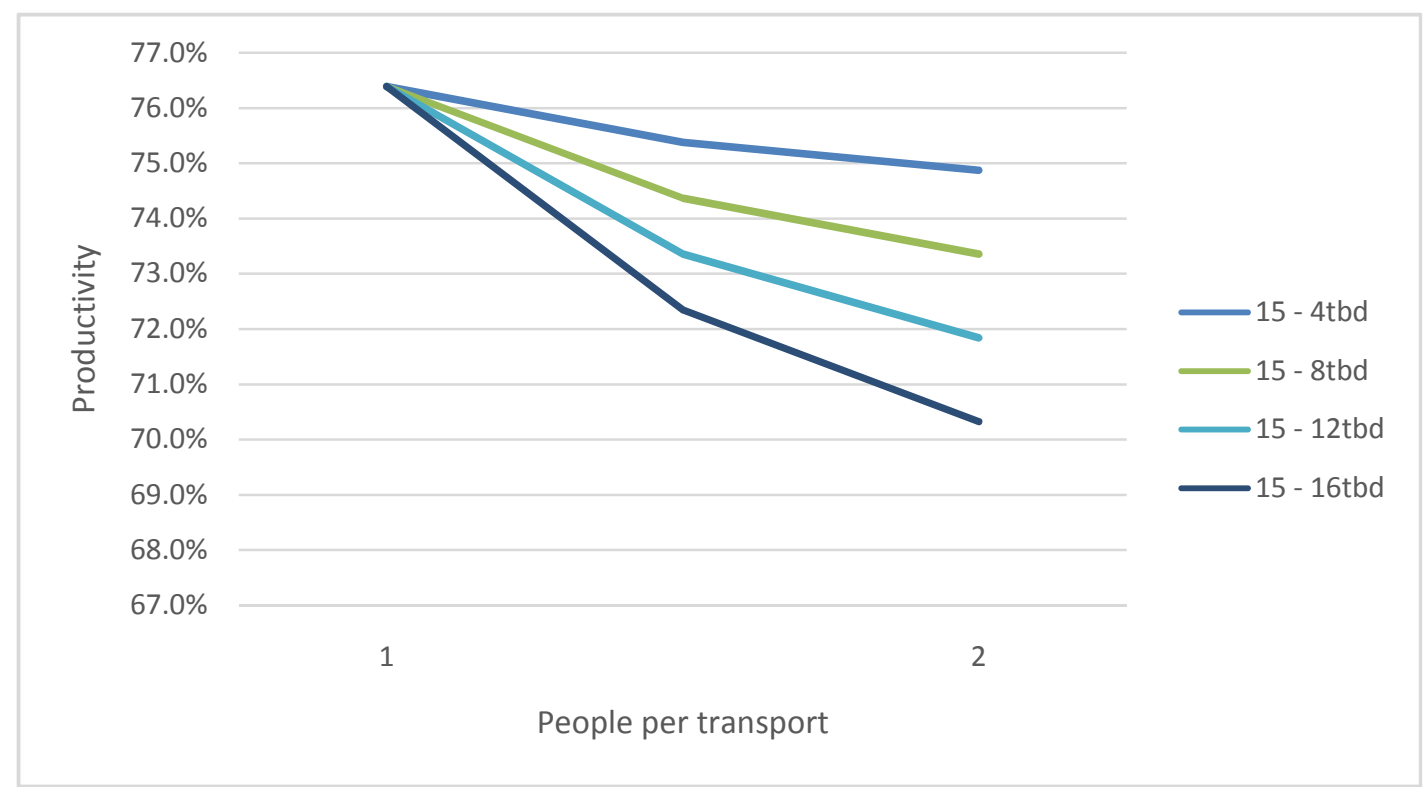

Figure 6: Labour productivity for 15 min initial travel time at Mine A

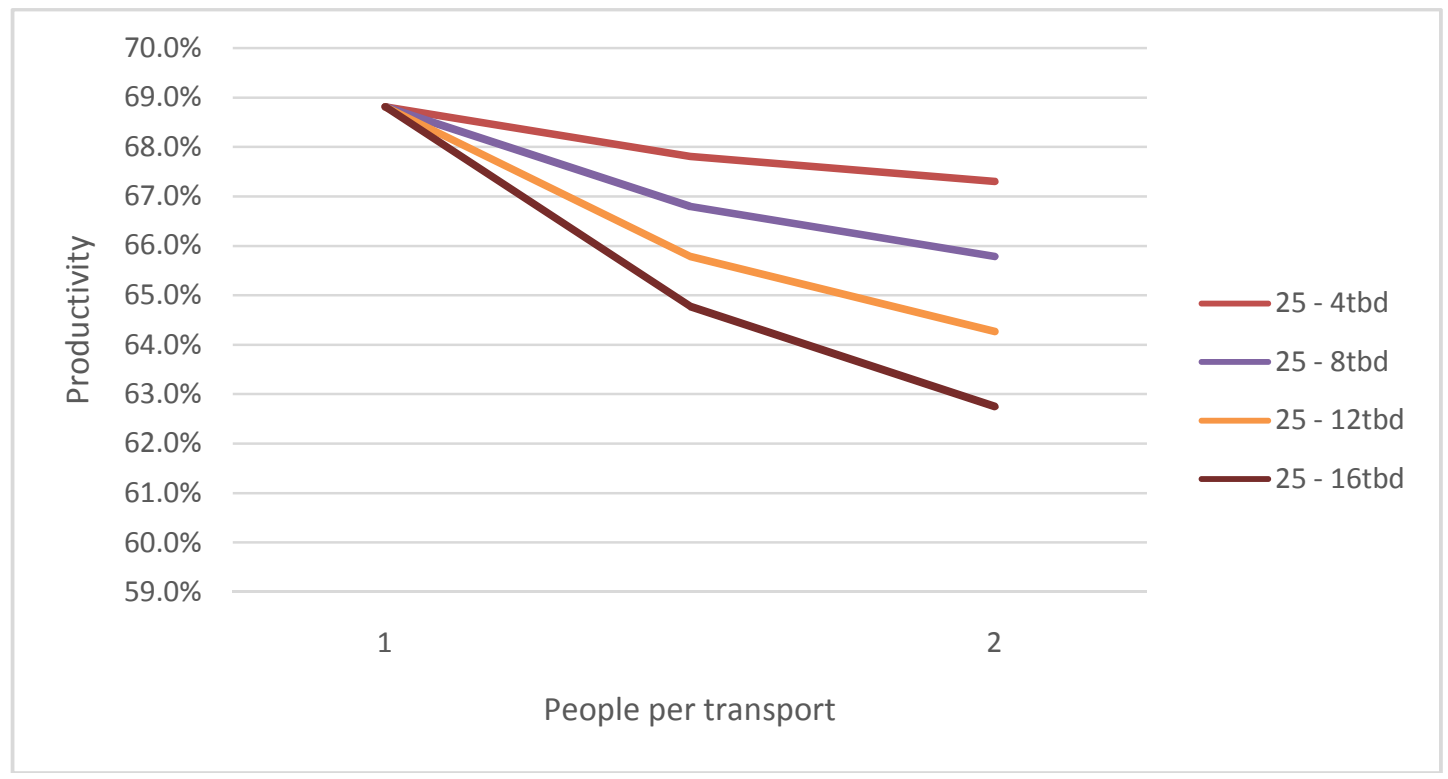

Figure 7: Labour productivity for 25 min initial travel time for Mine A

In Mine B when mine vehicle is used as means of transportation, similar trend was observed as in mine A for low and high intial travel times and average time between various work locations. For mine B the labour productivity was $72.3 \%$ with one operator per vehicle, which decreased to $70.6 \%$ when there are two persons in 
avehicle. With higher initial travel time, the labour productivity with one operator per vehicle was $63.5 \%$, but decreased to $61.8 \%$ when there are two persons in a vehicle. The results reveal that when mine A uses vehicle as means of transportation method, the effective time will be 6.7 and 6.1 hours of shift length for low and high initial travel times, respectively, while for mine $\mathrm{B}$ the effective working time will be 5.5 and 4.8 hours. It is anticipated that when the initial travel time is further increased beyond $25 \mathrm{~min}$., and the working areas are located far apart for a vehicle shared by operators, the labour productivity will be even lower and hence reduces the effective working time.

It was then analysed to compare the labour productivity when mine taxis and buses are used as means of transportation (Figure 8). For mine $\mathrm{A}$ it shows that, the labour productivity varies from $73 \%$ to $52.8 \%$ for intial travel time of 15 minutes and when transport time between work locations (tbd) varies from 4 to 16 minutes. As it can be seen in Figure 8, the slope of reduction is too gentle (compared to when mine vehicle is used) as there is no much time loss when a taxi stops to drop-off the operators. This is because for mine vehicle, a driver is also the operator in which he/she will need to find a parking slot before walking back to his/her work position. For mine taxis the driver is not among the operators, and therefore no time loss in finding a parking space. For Mine B (Table 4), the labour productivity varies from $71.8 \%$ to $46.5 \%$ with 2 to 5 operators per vehicle, respectively. In comparison to the results of the first method, it shows that mine taxi have low labour productivity compared to mine vehicle when these two systems are used to transport operators. This is because mine taxis carry more people per transport than mine vehicle hence have many stoppages when dropping the operators to the intended locations.

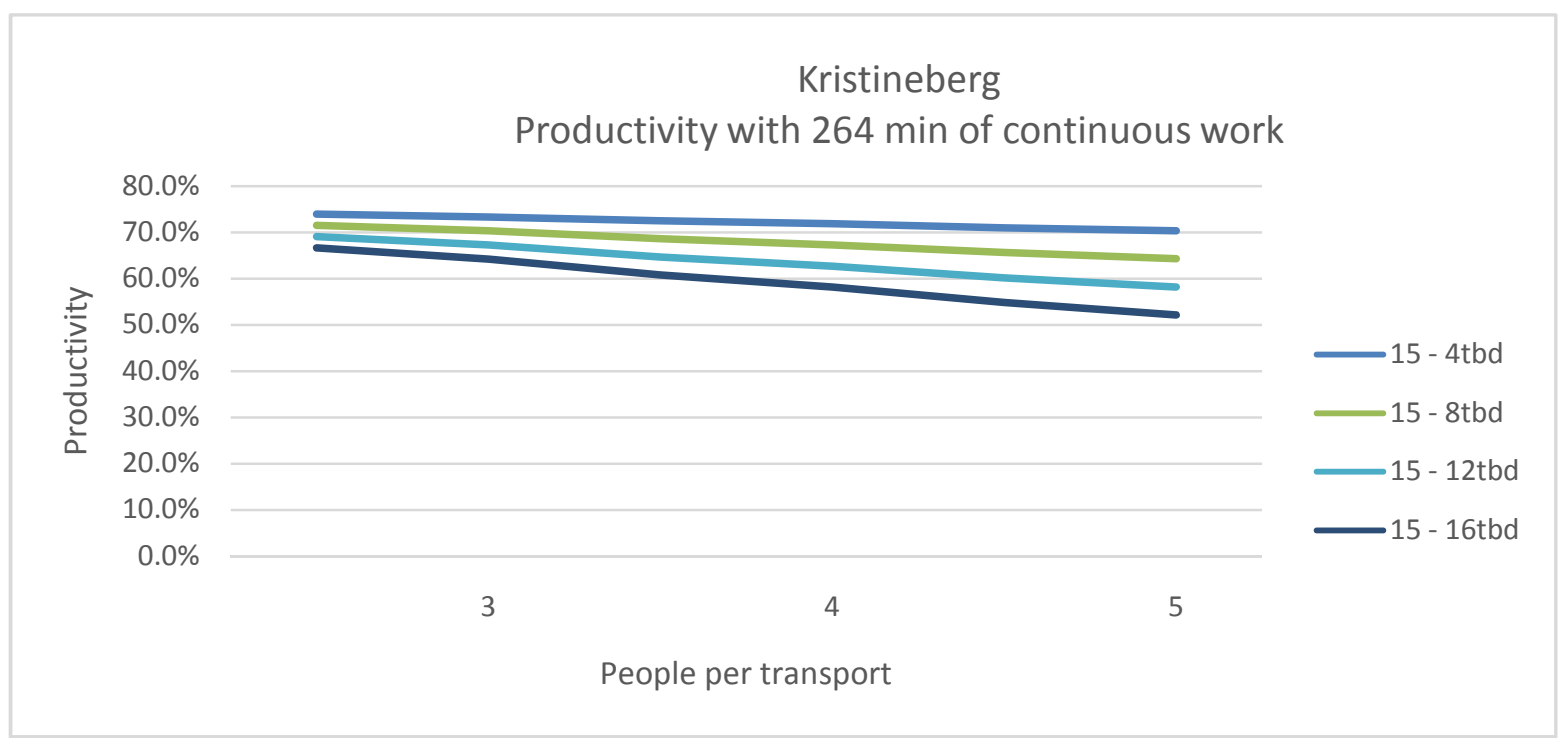

Figure 8: Labour productivity for mine taxi

The results for mine buses are also shown in Table 4. Unlike to the mine vehicle and mine taxis, mine bus can carry more people per trip. It can be seen that, the labour productivity is significantly affected. In comparison to mine vehicle and mine taxi, the labour productivity is decreased to $35.2 \%$ and $27.8 \%$ with an average of 10 operators per bus for mines $\mathrm{A}$ and $\mathrm{B}$, respectively. This is because of time loss due to many stoppages when dropping people to the various work 
locations. The use of mine buses as means of transportation may lead into cost reduction as more people will be carried per trip. Also leads into decrease in traffic as few machines will be moving within the ramps. The term traffic refers to the percentage of time lost when machines meet in the haul ways. The size of a bus could prohibit it to travel close to each work's machine for pickup. This would require an operator to get themselves to the pickup location.

Table 4: Productivity for initial work time of 25 min

\begin{tabular}{|c|c|c|c|}
\hline & $\begin{array}{c}\text { Labour Productivity at } \\
\text { Mine A (\%) }\end{array}$ & $\begin{array}{c}\text { Labour Productivity } \\
\text { at Mine B (\%) }\end{array}$ & $\begin{array}{c}\text { Number of } \\
\text { people }\end{array}$ \\
\hline \multirow{3}{*}{ Mine taxis } & 73 & 71.8 & 2 \\
\cline { 2 - 4 } & 65.8 & 62 & 3 \\
\cline { 2 - 4 } & 59.3 & 58.3 & 4 \\
\hline \multirow{3}{*}{ Mine buses } & 52.8 & 46.5 & 5 \\
\cline { 2 - 4 } & 61.2 & 54.8 & 6 \\
\cline { 2 - 4 } & 59.7 & 53.1 & 7 \\
\cline { 2 - 4 } & 58.2 & 51.3 & 9 \\
\cline { 2 - 4 } & 56.7 & 49.6 & 10 \\
\hline
\end{tabular}

The fourth mode of transport, which involves the monorail system was then analysed. The analysis was conducted for various shift lengths with variable mine depths. In monorail system, transportation of personnel by mounting man-riding can accommodate up to 20 men per carrier. For comparison purpose with other analysed transportation systems, the man-riding were limited to 10 men per carrier. The infrastructures and logistic issues, reveal that at Mine A, the operation of monorail extended up to a depth of $4330 \mathrm{~m}$ depth from the mine surface. At Mine B there is no limit for the extension of the monorail system. For comparison purpose it was also limited to work at the same depth as Mine A. Based on the mines infrastructures, the analysis was conducted at the depths of 1000, 2000, 3000, and 4330 meters from the mine surface. The monorail will first stop at a depth of $200 \mathrm{~m}$, and thereafter stops at every $500 \mathrm{~m}$ to drop operators at the work locations. The results are shown in Table 5.
It has been revealed that, monorail has higher labour productivity of up to $73 \%$ compared to mine buses. Also, monorail can be used for ore or waste transportation during the times when it is not transporting operators. As depicted in Table 5, the labour productivity observed to be low when mine depth increases because of the higher cycle time as a result of longer haul distance. It has been observed that the speed of a monorail system, average time to get off or in the monorail transport, and average distance between drop-off and pickup have great impact on the overall labour productivity. For shallow depths, the monorail can be operated at a low speed, while at a higher depth, the monorail can be operated at a higher speed in order to reduce the time to complete a cycle and hence labour productivity improvement.

The comparison of the transportation systems shows that the labour productivity is higher when few people are moved per trip. A mine vehicle or mine taxi may have greater possibility to plan its route, and 
may decrease early quits or late starts if the transport is planned to arrive at a certain work location. This could decrease the amount of time an operator quits early if no transport is available. This type of vehicle will not be suitable for deeper operations as a vehicle will consume longer time to complete one cycle while carry few people. In this case, mine buses can be used as a means of transportation. Despite that the buses carry more people per trip, they stop frequently, thus decreasing labour productivity. The buses also cannot drive close enough to the mine machines or mine faces which lead operators to walk longer distances and hence reduces their safety and working time. Monorail system is the safe way when it comes to quick transportation of personnel over long distances including vertical and horizontal curves. The monorail has other advantages (not covered in this analysis) such as less traffic disturbances since they are mounted in a roof, ore transportation during nonoperator transport periods, reduction of excavation dimension, lower support costs, less seismic risk and lower excavated rock volumes. Other advantages include reduction in ventilation air volumes, elimination of diesel exhaust fumes, reduction in heat load in underground workings, and reduction in quantity of rock required to be mined. The disadvantage of this option is that it has higher initial and expansion costs when mine depth increases. It has been revealed that for shallow depth mines, a good option to increase labour productivity is to keep the number of operators per trip as low as possible. For deep mines, a transport system that is faster, can accommodate few operators per trip, less possibility to meet traffic will be the better option to increase labour productivity.

Table 5: Results for monorail system

\begin{tabular}{|c|c|c|c|}
\hline $\begin{array}{c}\text { Shift length } \\
\text { (minutes) }\end{array}$ & $\begin{array}{c}\text { Distance to drop- } \\
\text { off }(\mathbf{m})\end{array}$ & $\begin{array}{c}\text { Labour Productivity } \\
\text { at mine A } \mathbf{( \% )}\end{array}$ & $\begin{array}{c}\text { Labour Productivity } \\
(\mathbf{\%}) \text { at mine B }\end{array}$ \\
\hline 264 & 1000 & $70.9-73.6$ & \\
\hline 264 & 2000 & $67-66.9$ & \\
\hline 264 & 3000 & $64.9-59.7$ & \\
\hline 264 & 4330 & $57.1-54.9$ & \\
\hline 228 & 1000 & & $64.8-70.2$ \\
\hline 228 & 2000 & & $61.8-64$ \\
\hline 228 & 3000 & & $53.5-61.8$ \\
\hline 228 & 4330 & & $47.9-56.3$ \\
\hline
\end{tabular}

\section{CONCLUSIONS}

The study investigated personnel transportation methods for underground operations by comparing labour productivity. The results show that:

- Mine vehicle can have a labour productivity of up to $76 \%$ of 8 -hour shift, while mine taxi reach up to $73 \%$. It has been revealed that for shallow depth mines, a good option to improve labour productivity is to keep the number of operators per trip as low as possible.

- Mine buses may lead into cost reduction as more people will be carried per trip and may decrease in traffic as few machines will be moving in the ramps. However, it is observed to have low labour productivity due to many stoppages. 
The size of a bus could prohibit it to travel close to the working location.

- It has been revealed that, monorail has higher labour productivity and can carry more people per carrier compared to other studied methods. The higher initial and expansion costs when mine is expanded need further analysis before this option is adopted.

- For deep mines, a transport system that is faster, can accommodate few operators per one transport, less possibility to meet traffic will be the better option to increase labour productivity.

Future study may involve the detailed evaluation on the capital and operating costs of the analysed transportation systems.

\section{ACKNOWLEDGEMENT}

The authors would like to acknowledge the $\mathrm{I}^{2}$ Mine project within the EU $7^{\text {th }}$ framework programme for funds as it in great extent help towards completion of this work.

\section{REFERENCES}

Aljuhani M. (2002). Labour's utilization and labour's productivity of a gold mine in Saudi Arabia. The Journal of South African Institute of Mining and Metallurgy, volume 102(5): 307-310. https://hdl.handle.net/10520/AJA00382 23X_2699.

Angelov A.A. and Naidoo K. (2010). Plan compliance process for underground coal mines. Journal of the Southern African Institute of Mining and Metallurgy. 110(5): 241-250. ISSN 2411-9717.

Bureau of Labor Statistics (2011). Productivity and costs by industry. US Department of Labour. Available online at https://www.bls.gov/bls/newsrelease/prin.htm. Retrieved on 25th June 2020.
Bradley C. and Sharpe A. (2009). A detail analysis of the productivity performance of mining in Canada. http://www.csls.ca/reports/csls20098.pdf.

Chanda E.K. and Besa B. (2011). A computer simulation model of a monorail-based mining system for decline development. International Journal of Mining Reclamation and Environment, 25(1): 52-68. https://doi.org/10.1080/17480930.2010. 503386.

Chanda E.K. and Burke P.A (2007). Electro-monorail; An alternative operating system for deep mining. Australian Centre for Geomachanics Publications. ISBN: 978-0-9804185-21.

Chanda E.K. and Roberts M. (2005). Evaluation of monorail haulage system in metalliferous underground mining. Proceeding of hoist and haul Conference, 5-7 September, Perth, 3944. The Australasian Institute of Mining and Metallurgy, Melbourne, Australia.

Coelli T.J., PrasadaRao D.S., O’Donnell C.J. and Battese G.E. (2005). An introduction to efficiency and productivity analysis. New York: Springer Science and Business Media.

Ercelebi S.G. and Kirmanli C. (2000). Review of surface mining equipment selection techniques. Mine Planning and Equipment Selection, Pasamehmetoglu et al. (eds). Balkema, Rotterdam, 547-553.

Misungwini C., Minnitt R.C.A. and Woodhall M. (2006). Technical operating flexibility in the analysis of mine layouts and schedules. International Platinum Conference 'Platinum Surges Ahead', the South African Institute of Mining and Metallurgy.

Noort D. and McCarthy P. (2008). The critical path to automated underground mining. Paper presented at The First International Future Mining 
Conference, November, Sydney, Australia, 179-182.

Rupprecht S.M. (2010). Safety considerations in underground logisticsa look at vertical, horizontal and instope transportation systems, paper presented at the SAIMM Conference, second hardrock safety, 4-5 August 2010, Emperors palace Johannesburg.

Salama A., Nehring M. and Greberg J. (2014). Operating value optimisation using simulation and mixed integer programming, International Journal of
Mining, Reclamation and Environment, 28(1): 25-46. https://doi.org/10.1080/17480930.2013. 768019

Syed A., Grafton Q. and Kalirajan, K. (2013). Productivity in the Australian mining sector. BREE, Canberra, Commonwealth of Australia.

Tomlison P.D. (1998). Equipment management: Breakthrough maintenance management strategy for the $21^{\text {st }}$ century, Kendall/Hunts Publishing Company, Iowa, USA. 